\title{
Peningkatan Koefisien Gaya Angkat Aerofoil Kennedy-Marsden dengan Zap Flap
}

\author{
Catur Setyawan K ${ }^{1}$, Djoko Sardjadi² \\ Lab. Perancangan Jurusan Teknik Mesin \\ Fakultas Teknik Universitas Negeri Jakarta \\ ${ }^{2}$ Prodi Aeronotika dan Astronotika. Fakultas Teknik Mesin dan Dirgantara, Institut Teknologi \\ Bandung \\ Jl. Ganesha 10, Bandung \\ Email: catur_sk@yahoo.co.id
}

\begin{abstract}
Abstrak
Makalah ini membahas peningkatan prestasi aerodinamika aerofoil dengan menggunakan zap flap. Penggunaan zap flap ini memungkinkan dipertahankannya bentuk asli aerofoil pada saat flap tidak digunakan. Sedangkan pada saat zap flap dijulurkan, akan terjadi peningkatan gaya angkat akibat bertambah panjangnya chord aerofoil dan berubahnya kelengkungan aerofoil. Pemakaian zap flap ini juga akan membuat aerofoil masih mempunyai sifat sebagai aerofoil satu elemen meskipun flap telah digunakan. Dengan sifat ini diharapkan penambahan gaya angkat yang diperoleh tidak akan berpengaruh banyak terhadap koefisien-koefisien aerodinamika aerofoil yang lain.
\end{abstract}

Aerofoil yang digunakan dalam penelitian ini adalah aerofoil Kennedy-Marsden yang telah dimodifikasi. Dengan memvariasikan panjang zap flap yang dijulurkan, dilakukan analisis perubahan prestasi aerodinamika aerofoil.

Pada penelitian ini, analisis karakteristik aerodinamika aerofoil dihasilkan dari perhitungan numerik menggunakan program MSES. Persamaan atur yang dipecahkan dalam solver MSES ini adalah kombinasi persamaan Euler dan persamaan lapisan batas

Kata Kunci: zap flap, koefisien gaya angkat,

\section{PENDAHULUAN}

Peningkatan prestasi aerodinamika aerofoil dapat juga dilakukan dengan memakai suatu perangkat penambah gaya angkat pada sayap (high lift device). Ide sistem ini sangat sederhana yaitu mengubah satu atau beberapa bagian sehingga terbentuk profil baru yang diinginkan. Perubahan ini dilakukan dengan memanfaatkan sistem kinematika tertentu dimana pada saat yang diinginkan, misalnya saat terbang jelajah, geometri aerofoil yang baru dapat dikembalikan ke bentuk basic aerofoil. Beberapa konfigurasi perangkat penambah gaya angkat yang dikenal saat ini misalnya, slotted flap, fowler flap, kruger flap, slat, zap flap dan sebagainya.

Pemakaian zap flap ini memungkinkan untuk mempertahankan bentuk asli aerofoil pada saat flap tidak digunakan. Sedangkan pada saat zap flap dijulurkan, akan terjadi peningkatan gaya angkat akibat penambahan panjang chord aerofoil dan perubahan kelengkungan aerofoil. Pemakaian zap flap 
ini juga akan membuat aerofoil masih mempunyai sifat sebagai aerofoil satu elemen meskipun flap telah digunakan. Dengan sifat ini diharapkan penambahan gaya angkat yang diperoleh tidak akan berpengaruh banyak terhadap koefisienkoefisien aerodinamika aerofoil yang lain.

Aerofoil yang digunakan dalam penelitian ini adalah aerofoil Kennedy-Marsden yang telah dimodifikasi. Dengan memvariasikan panjang zap flap yang dijulurkan, dilakukan analisis perubahan prestasi aerodinamika aerofoil.

\section{AIRFOIL DENGAN FLAP}

\subsection{Perangkat penambah gaya angkat}

Untuk terbang dengan kecepatan rendah, pesawat terbang membutuhkan tambahan koefisien gaya angkat sayap untuk mempertahankan ketinggiannya. Untuk menambah koefisien gaya angkat ini biasanya digunakan perangkat penambah gaya angkat (high lift device). Penggunaan perangkat penambah gaya angkat ini terutama karena kebutuhan gaya angkat yang besar hanya dibutuhkan pada saat tinggal landas dan mendarat. Sedangkan pada saat terbang jelajah, perangkat penambah gaya angkat dapat disimpan kembali untuk memperoleh efisiensi aerodinamika terbang jelajah yang lebih baik.

Perangkat penambah gaya angkat ini pada dasarnya akan menambah kelengkungan camber aerofoil sayap. Penambahan in bisa dilakukan untuk kelengkungan bagian depan sayap (leading edge) dengan menggunakan slat, atau kelengkungan bagian belakang sayap dengan menggunakan flap. Ada berbagai jenis flap yang dikenal, misalnya plain flap, fowler flap, slotted flap, split flap dan zap flap

\subsection{Aerofoil dengan Zap Flap}

Ide dasar dari zap flap adalah untuk mempertahankan bentuk aerofoil pada saat flap tidak digunakan. Cara kerja zap flap adalah dengan mengatur panjang chord aerofoil dengan menarik dan menjulurkan bagian trailing edge. Prestasi zap flap dipengaruhi oleh panjang penambahan chord dan kemiringan bagian yang dijulurkan.

Penambahan panjang chord akan menambah koefisien gaya angkat tapi tidak linier. Penambahan panjang ini dibatasi oleh kekuatan struktur flap. Karena tipis tidak akan dapat menahan beban yang bekerja pada flap.

Kemiringan bagian zap flap akan menambah koefisien gaya angkat jika makin miring. Sesuai dengan konsep aerofoil tipis makin miring bagian trailing edge akan makin besar gaya angkat yang dihasilkan .

\section{METODE KOMPUTASI}

\subsection{Software}

Metode analisis dilakukann dengan menggunakan software CFD (computational fluid dynamics), MSES. Software ini dikembangkang pertama kali oleh Drella di MIT. Software ini menyelesaikan persamaan Euler. Dalam melakukan perhitungan karakteristik aliran di dinding aerofoil, software ini menggunakan metode viscous inviscid iteration.

Software yang dipergunakan dalam penelitian ini merupakan software MSES yang telah dimodifikasi oleh A. Sudarmawan (PT Dirgantara Indonesia) sehingga bisa dijalankan pada platform windows.

\subsection{Permodelan Aerofoil}

Data airfoil yang diinputkan adalah data koordinat 2 dimensi. Sedangkan bidang 
perhitungan berupa persegi empat dengan ukuran 6 x 6 panjang chord. Mesh domain perhitungan berbentuk segi empat dengan variasi ukuran mengikuti aturan cosinus.

\subsection{Geometri Zap Flap}

Aerofoil yang digunakan pada penelitian ini adalah aerofoil Kennedy-Marsden yang telah dimodifikasi. Geometri aerofoil Kennedy-Marsden hasil modifikasi ditampilkan pada gambar 1. Zap flap aerofoil ini dimulai dari posisi 0.96 chord sampai ke trailing edge. Pemilihan posisi ini karena ketebalan aerofoil paling kecil pada posisi 0.96 chord serta untuk mempertahankan keberadaan bentuk divergent trailing edge. Bentuk divergent trailing edge diharapkan dapat memberi tambahan gaya angkat ketika zap flap dijulurkan. Variasi panjang zap flap yang dilakukan yaitu $5 \%$ c, $10 \%$ c, $15 \%$ c, $20 \%$ c, $25 \%$ c dan 30\%c. Geometri zap flap ditampilkan pada gambar 2. Pengaruh kemiringan zap flap terhadap garis chord tidak dilakukan pada perhitungan ini. Kemiringan zap flap pada penelitian kali ini adalah kemiringan maksimum yang mungkin diperoleh. Yaitu dengan mengambil kemiringan permukaan atas aerofoil.

Pada perhitungan kali ini pengaruh ketebalan aerofoil utama dengan zap flap tidak diperhitungkan. Jadi tidak ada bentuk permukaan aerofoil yang tidak mulus.

\section{HASIL ANALISIS}

Gambar 3 menunjukkan pengaruh zap flap terhadap penambahan koefisien gaya angkat. Dari grafik ini terlihat adanya penambahan $\mathrm{c}_{1}$ sekitar 0.25 akibat pemakaian zap flap sepanjang 5\% chord dan adanya penambahan sekitar koefisien rata-rata 1 untuk zap flap $25 \%$ chord. Penambahan koefisien gaya angkat akibat penambahan zap flap akan berubah secara linier tetapi tidak konstan. Penambahan per segmen 5\% chord, menunjukkan bahwa penambahan $5 \%$ pertama (dari $0 \%$ c menjadi $5 \%$ c) memberikan tambahan $c_{1}$ sebesar 0.27 untuk segmen ke 5 (dari 20\%c menjadi $25 \%$ c) tambahan $c_{1}$ yang diperoleh sebesar 0.15 . Dengan kondisi ini perlu dilakukan penelitian mengenai efektifitas panjang zap flap terhadap penambahan gaya angkat. Karena akan ada saat dimana penambahan panjang zap flap tidak akan memberikan tambahan gaya angkat.

Gambar 4 menunjukkan grafik drag polar aerofoil Kennedy-Marsden yang dipasangi zap flap. Penambahan koefisien gaya hambat pada segmen $5 \%$ c pertama (dari 0\%c menjadi 5\%c) sebesar 10 drag count pada saat $c_{d}$ min. Penambahan $c_{d}$ per segmen 5\%c akan makin kecil. Penambahan $\mathrm{c}_{\mathrm{d}}$ dari $0 \% \mathrm{c}$ menjadi $25 \% \mathrm{c}$ sebesar 45 drag count.

Gambar 5 menunjukkan pengaruh zap flap terhadap penambahan koefisien momen. Penambahan momen tukik aerofoil dengan zap flap akan makin kecil (per segmen 5\%c). Grafik 5 ini menunjukkan bahwa untuk sudut serang yang makin tinggi pengaruh zap flap terhadap penambahan $\mathrm{c}_{\mathrm{m}}$ makin berkurang. Harga $c_{m}$ hampir sama di daerah alpha stall.

Gambar 6 menunjukkan pengaruh zap flap terhadap $\mathrm{c}_{1} / \mathrm{c}_{\mathrm{d}}$. Variasi harga $\mathrm{cl} / \mathrm{cd}$ maksimum akibat zap flap sekitar $10 \%$. Sedangkan harga cl untuk cl/cd maksimum makin besar dengan penambahan panjang zap flap.

Gambar 7 dam 8 menunjukkan distribusi tekanan permukaan aerofoil pada sudut serang $0^{\circ}$ dan $4^{\circ}$. Dari grafik ini terlihat bahwa tekanan permukaan atas makin tinggi dengan penambahan panjang zap flap. Sedang di permukaan bawah pada posisi $\mathrm{x} / \mathrm{c}$ $=0.95$, ada bentuk distribusi yang menonjol untuk semua jenis zap flap. Distribusi yang menonjol ini akibat kelengkungan permukaan bawah pada posisi sambungan 
antara aerofoil dengan zap flap, dimana aliran diperlambat.

\section{KESIMPULAN}

Penambahan panjang zap flap yang konstan akan memberikan penambahan koefisien gaya angkat yang makin kecil. Untuk itu perlu dilakukan optimasi panjang zap flap yang akan dipasang.

Mengingat bentuk zap flap yang tipis dan beban yang dihasilkannya cukup besar. Pemilihan bahan untuk membuat zap flap yang kuat dan kaku sangat diperlukan.

Pada pelelitian ini bentuk zap flap yang dianalisis adalah bentuk lurus. Untuk selanjutnya bentuk zap flap mungkin dikembangkan menjadi bentuk yang melengkung (berbentuk kurva). Dengan bentuk kurva diharapkan penambahan gaya angkat akan semakin besar juga.

\section{Daftar Pustaka}

1. Kuethe, A.M. dan Schetzer, J.D., "Foundations of Aerodynamics", John Wiley \& son, Inc, 1959

2. Clancy, L.J., " Aerodynamics", Pitman , 1975 


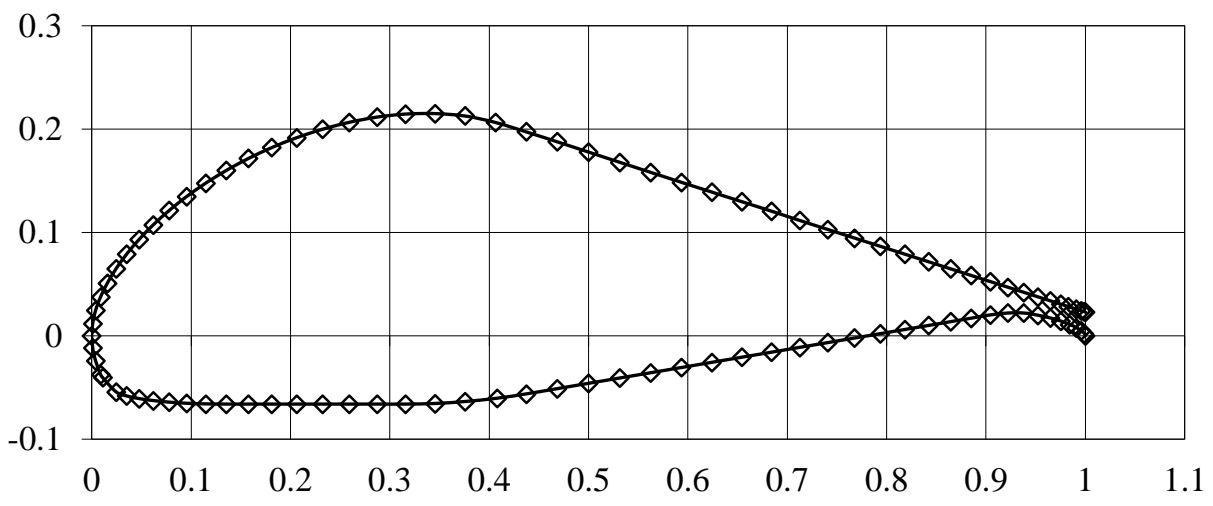

Gambar 1 Airfoil Kennedy-Marsden Mod

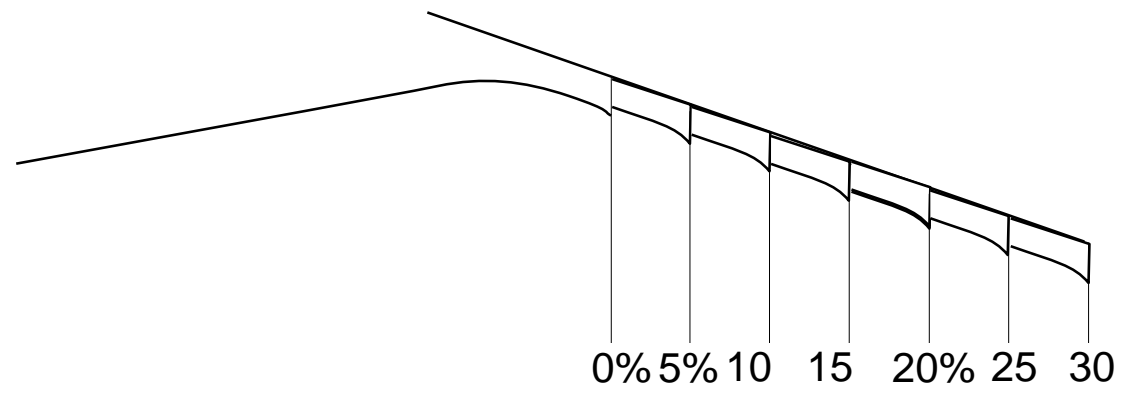

Gambar 2 Geometri trailing edge aerofoil Mod 1a dengan zap flap

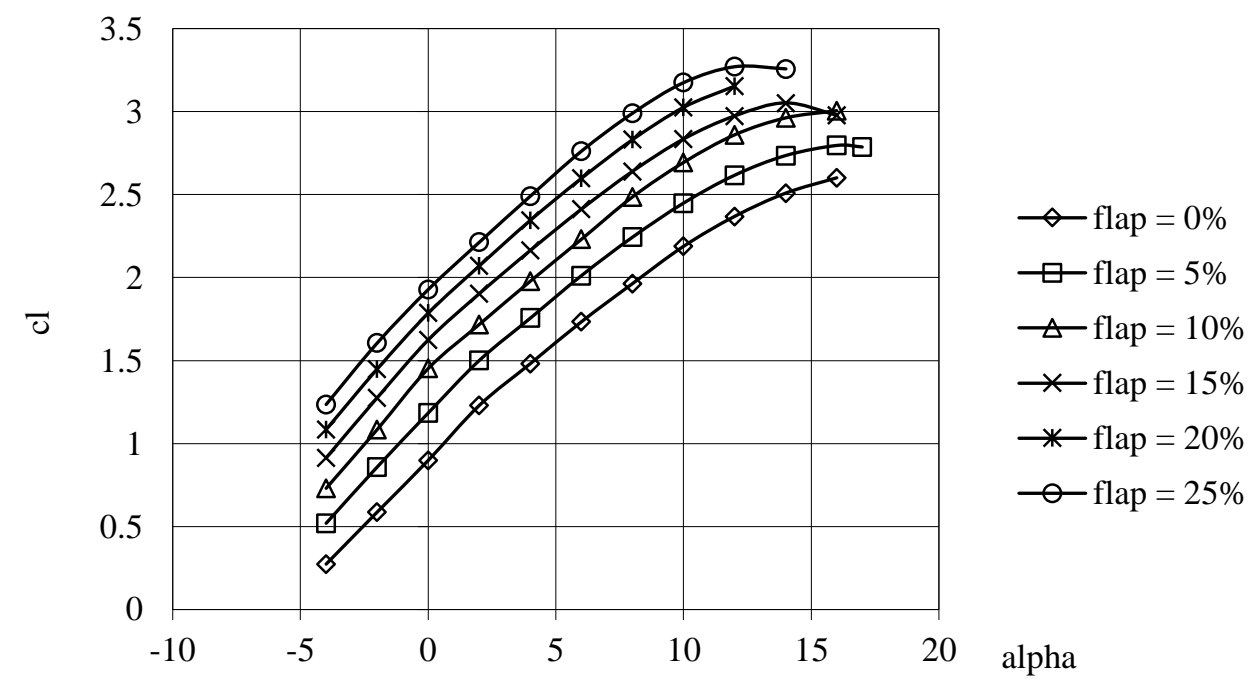

Gambar 3 Grafik cl - sudut serang, variasi panjang flap 


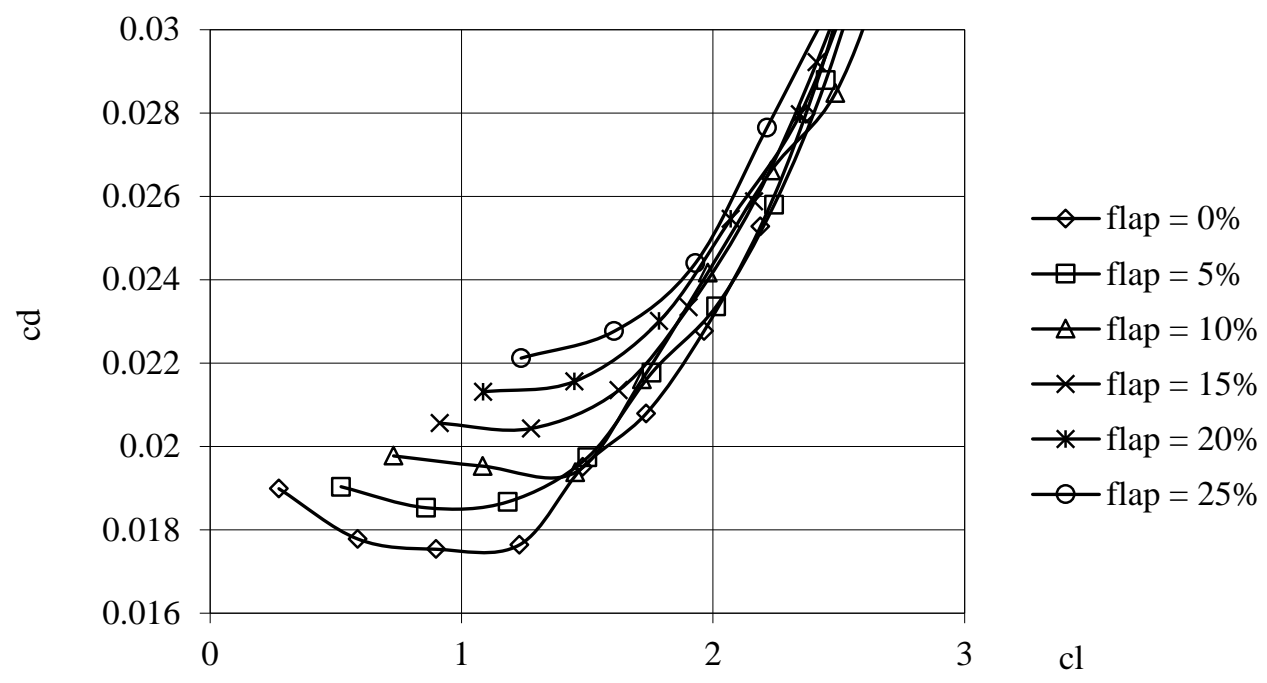

Gambar 4 Grafik drag polar, variasi panjang flap

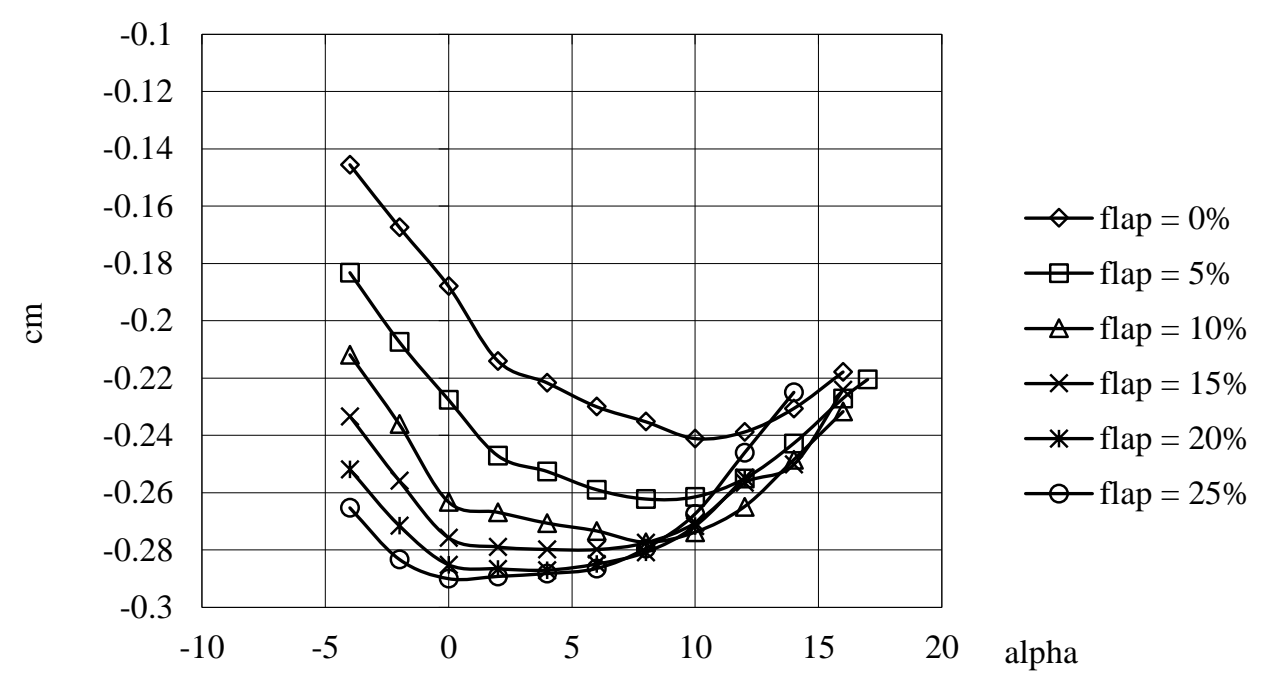

Gambar 5 Grafik cm - sudut serang, variasi panjang flap 


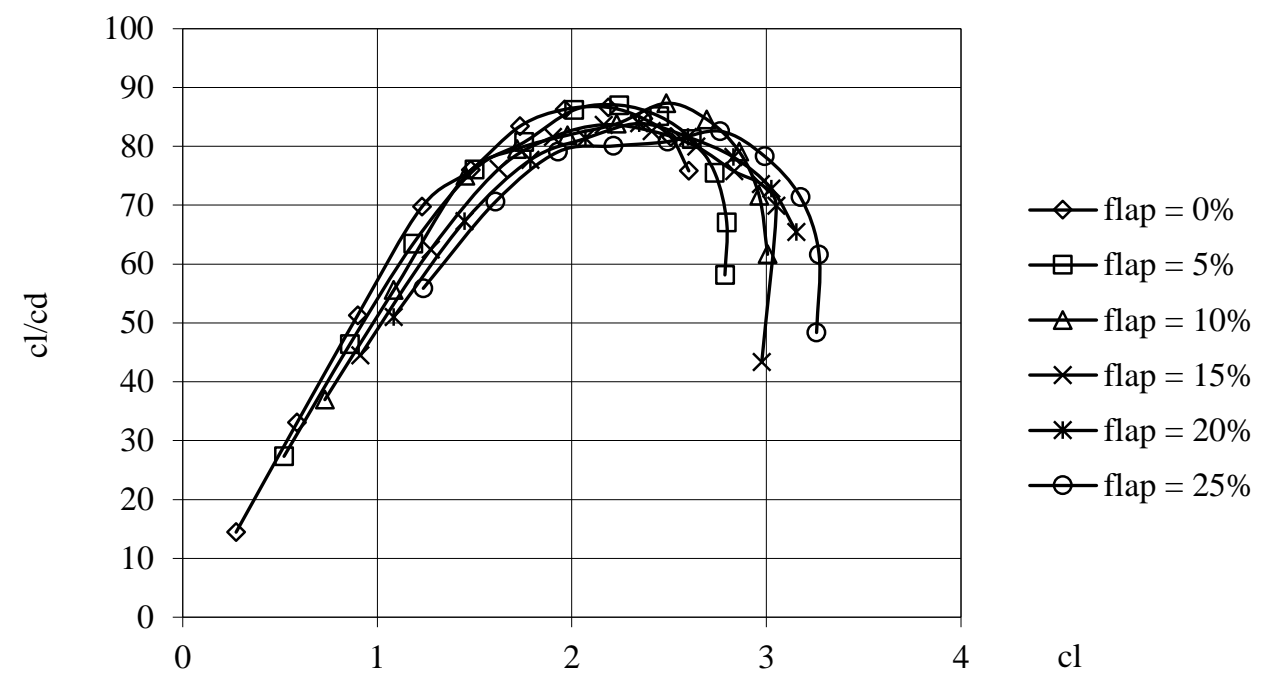

Gambar 6 Grafik cl - cl/cd, variasi panjang flap

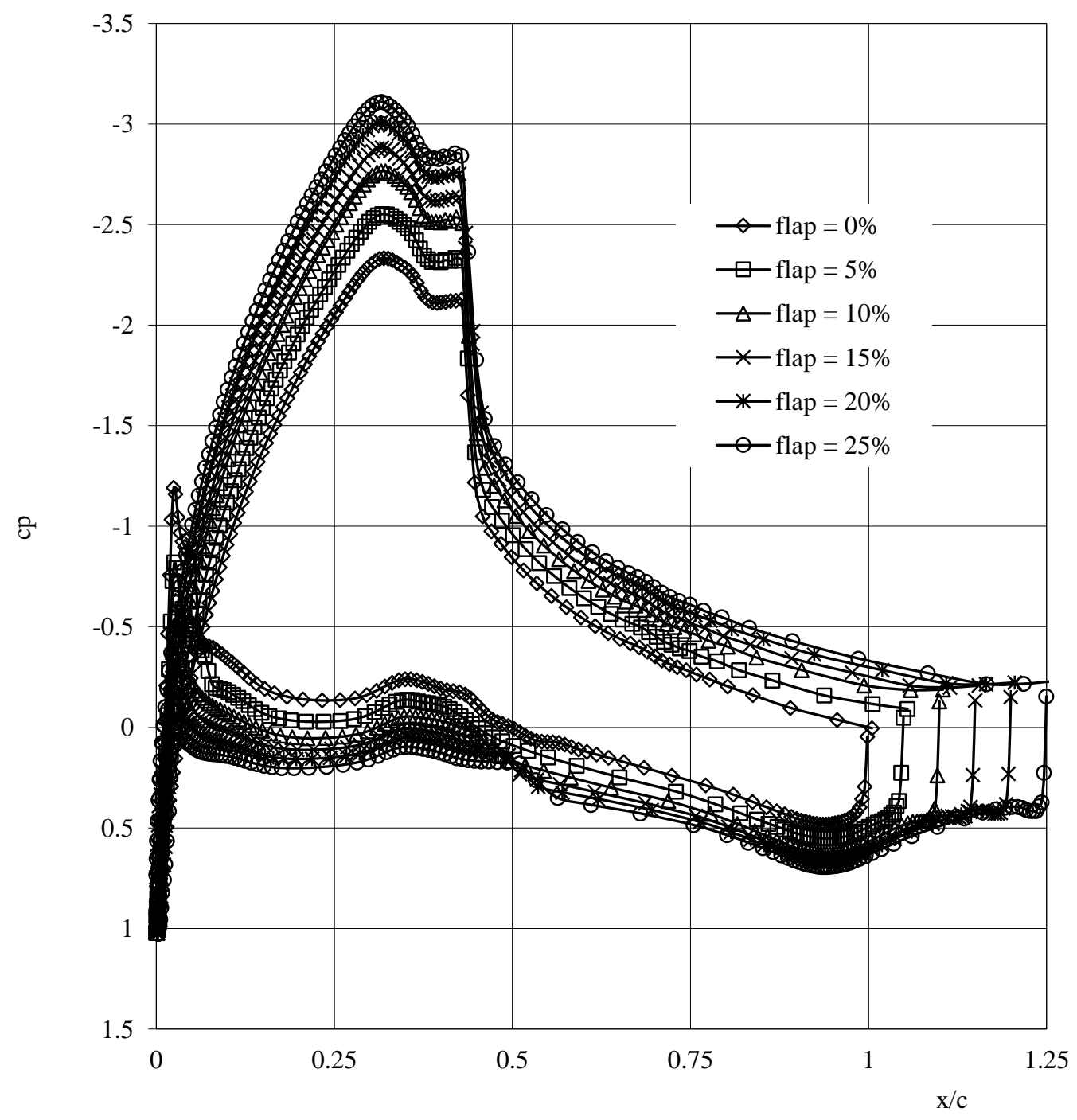

Gambar 7 Distribusi tekanan permukaan aerofoil, sudut serang $=0 \mathrm{deg}$ 


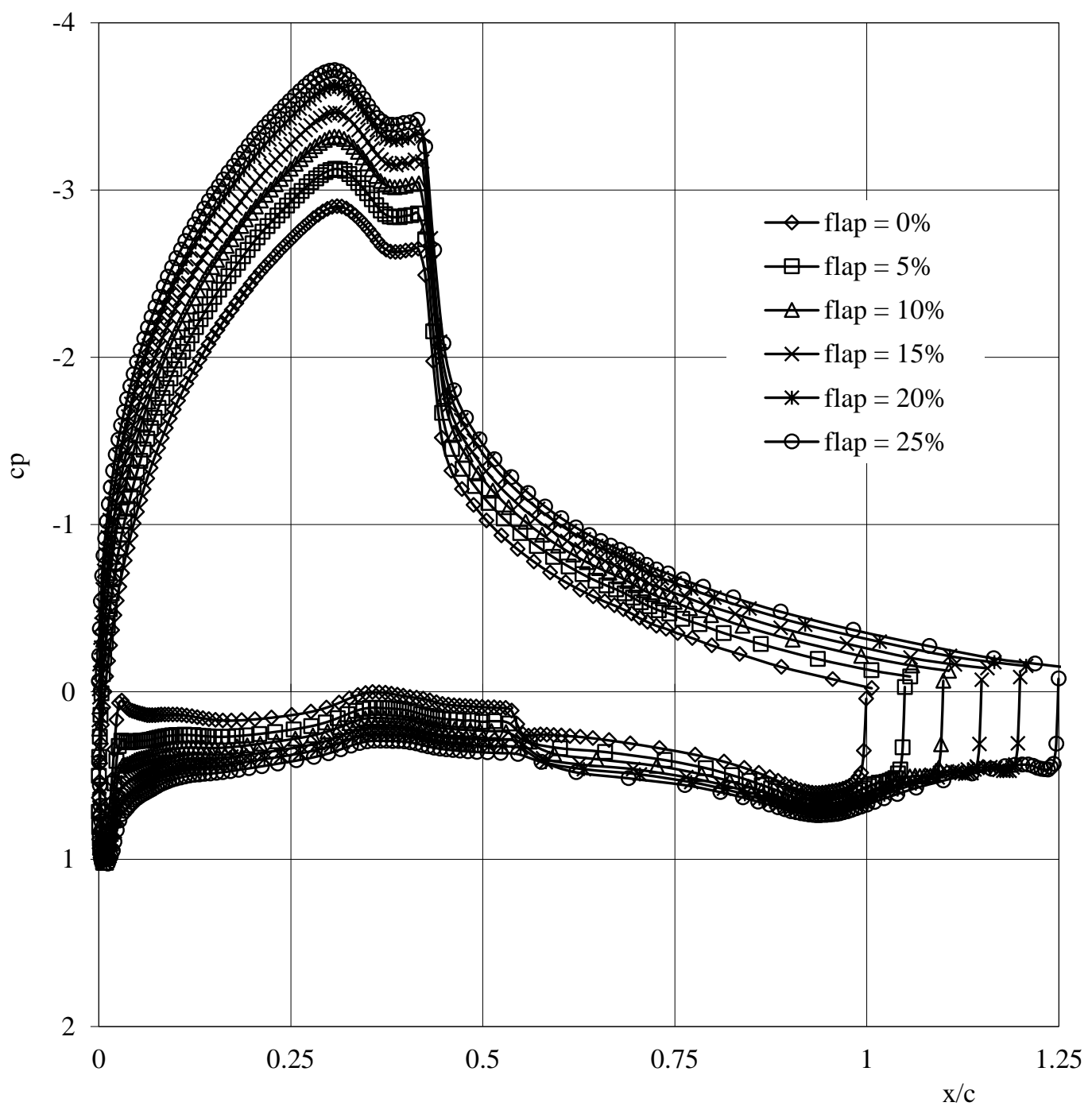

Gambar 8 Distribusi tekanan permukaan aerofoil, sudut serang $=4 \mathrm{deg}$ 